\title{
A Variational Model for Free-Edge Interlaminar Stress Analysis in General Symmetric and Thin-Ply Composite Laminates
}

\author{
M. Hajikazemi*, W. Van Paepegem \\ Department of Materials, Textiles and Chemical Engineering, Faculty of Engineering and \\ Architecture, Ghent University, Technologiepark Zwijnaarde 903, Ghent, Belgium
}

\begin{abstract}
A variational model is developed to exactly determine both stress and displacement fields at free edges of general symmetric composite laminate strips under thermomechanical loads. By partitioning the total stresses in a composite with free edges into unperturbed (without free edge) and perturbation stresses and using the minimum complementary energy principle, the optimal stress and displacement fields are derived that exactly satisfy equilibrium, compatibility, boundary and continuity conditions. The paper extends the theory of stress-based variational stress transfer so that the effects of both applied traction and displacement loads can be considered. It has been also shown how the displacement field can be determined for a stress-based variational approach. The results are compared to refined finite element results. The superiority of the developed method over finite element method, both in terms of accuracy and computational efficiency, is discussed. The method is also applicable to thin-ply laminates and is computationally efficient.
\end{abstract}

Keywords: Thin-ply composite laminates; Free-edge; Interlaminar stress transfer; Analytical approach; Variational method; Delamination

\section{Introduction}

Stress concentrations like the free-edge effect may result in hazardous consequences since out ofplane or interlaminar stresses usually face quite weak material strength properties, which can

\footnotetext{
*Corresponding Author, Tel: +32479659875, E-mail address: Mohammad.hajikazemi@ugent.be, Postal address: Technologiepark 903, 9052 Zwijnaarde, Ghent, Belgium.
} 
eventually lead to premature failure due to corresponding interlaminar failure modes such as delamination. Although the free-edge problem is known from the 1970s, no analytical solutions exist that simultaneously satisfy the 3D elasticity governing equations along with all the traction free boundary conditions and the interface continuity conditions, due to the inherent complexities involved in the problem. Therefore, most approaches have been developed based on quasi-3D models or reduced 2D plate models [1] applied to a long rectangular composite laminate in which zero gradients along the axial coordinate are assumed. A comprehensive literature review on the methods proposed for determining the free-edge stress fields has been presented in Refs $[1,2]$. Generally, approaches to the problem include the approximate elasticity solutions [3, 4], different modifications of Pagano's theory [5-7] based on the Reissner variational principle, displacementbased equivalent single-layer (ESL) models [8], displacement-based layer-wise (LW) models [9], LW stress-based variational models $[10,11]$ based on the minimum complementary energy principle, semi-analytical [12] and numerical [13] displacement-based approaches (e.g. FEM).

Among the developed analytical and numerical approaches, the LW stress-based variational method $[10,11]$ based on the minimum complementary energy principle [14] is potentially more accurate for free-edge problems where there are zero traction boundary conditions. Contrary to displacement-based approaches, the approximate stress field derived with variational approaches satisfy exactly all the necessary equilibrium equations, interlaminar continuity and boundary conditions including zero-stress conditions at the free edges as well as the top and bottom surfaces of laminates. This approach was first introduced by Hashin [14] in 1985 for the analysis of cracked two-layer cross-ply laminates under uniaxial tension and further developed by many authors for analyzing cracked laminates with general lay-ups, see for example [15-18] as the most complete variational models developed so far. Kassapoglou and Lagace $[10,19]$ were the first who applied 
the variational approach for analyzing stress concentrations near free edges. The reader is referred to the recent publications $[1,2,16,17]$ for a detailed review of the developments in variational approach for the free-edge $[1,2]$ and matrix cracking $[16,17]$ stress transfer problems.

The main drawback of the available stress-based variational models is that they predict only stress components. It is due to this fact that the stress-based variational method based on the minimum complementary energy principle does not require the corresponding displacement field, nor does it relate the assumed stress distribution to the strain-displacement equations. Secondly, all of the developed variational models like other approaches discussed in this paper, have been formulated, not to completely resolve the free-edge or matrix cracking stress transfer problem, but just partially to eliminate the dependence of the stress field on the through-thickness coordinate of the laminate. Therefore, the interlaminar stress transfer problem can be reduced to a simple boundary value problem which is dependent only on the axial or transverse coordinate of the assumed laminate. For the variational free-edge stress transfer analysis [10, 19] unlike the developed variational ply cracking models [15-18], this boundary value problem leads to a set of non-homogeneous differential equations as the Euler's equation(s) from the variational calculus. Indeed, the more layers considered, the more non-homogeneous equations will appear. Therefore, one difficulty in available variational models for the free-edge stress transfer problem is because of the increased number of non-homogeneous differential equations involved, which must be analytically solved. Moreover, there is not a systematic way to obtain and solve these governing equations and thus unlike the procedure introduced in Ref. [7], it is not possible to develop a software based on the current variational formulations. It simply means that the results obtained from the available variational models regarding the free-edge stress transfer $[1,2,10,19]$ are approximate and thus, do not reproduce very refined finite element results. In addition, due to 
implementation of the minimum complementary energy principle, all of the developed stressbased variational models either for analyzing cracked laminates or free-edge stress fields are formulated for traction loading conditions. However, most of the experiments for free-edge analysis are performed under displacement loading conditions.

In this paper, a stress-based variational model is developed to accurately predict the complete state of stress and displacement in a general symmetric (possibly made of thin-ply) composite laminate containing free edges under uniaxial end stretching/shortening while the effects of thermally induced residual stresses are exactly taken into account. First, an admissible stress field containing some unknown functions is constructed that satisfies the stress equilibrium and all the traction boundary and continuity conditions. Then, by invoking the minimum complementary energy principle, the optimal stress state is achieved. An analytical approach is implemented to obtain the governing equations in a systematic way and consequently, the model can use the benefits of the ply refinement technique [7]. By partitioning the total stresses in a composite with free edge into unperturbed (without free edge) and perturbation stresses, it is possible to obtain a set of homogeneous fourth order differential equations with constant coefficients which are solved analytically. Moreover, it is shown how the strain and displacement fields can be determined when using a variational model based on the minimum complementary energy principle. The results obtained from the developed approach are compared to the available refined finite element results $[7,20,21]$ for cross-ply, angle ply and quasi-isotropic laminates. The comparisons of stress and displacement fields under both mechanical and thermal loads show an excellent agreement. It should be mentioned that the assumed stress and displacement fields satisfy stress equilibrium, strain-displacement relations and all the boundary and continuity conditions and additionally, the minimum complementary energy principle and a ply refinement methodology are implemented to 
approach the exact solution. Moreover, the run time of the developed model is less than one second for all considered cases when using a double cores Central Processing Unit (CPU) with 4 Gigabytes Random Access Memory (RAM) in a 64-bit operating system. Thus, for stress transfer analysis in symmetric laminates with free edges, the present approach has both high accuracy and computational efficiency.

\section{Theoretical Formulation}

An arbitrary symmetric laminate having $2 \mathrm{~N}$ perfectly bonded layers is considered. Since the laminate is symmetric, only the upper set of $\mathrm{N}$ layers will be considered, as shown in Fig. 1. A rectangular Cartesian coordinates system with the origin located in the mid length of the laminate , is selected. The x-coordinate defines the axial or loading direction, the y-coordinate defines the in-plane transverse (normal to free edges) direction and the z-coordinate defines the throughthickness direction. There are N-1 interfaces at the top half of the symmetric laminate $(\mathrm{z}>0)$ which are shown by $\mathrm{z}=\mathrm{z}_{\mathrm{i}} ; \mathrm{i}=1,2 \ldots \mathrm{N}-1$. The plane of symmetry (mid-plane) is shown by $\mathrm{z}=\mathrm{z}_{0}=0$ and the external top surface is specified by $\mathrm{z}=\mathrm{Z}_{\mathrm{N}}=\mathrm{h}$. The total thickness of the laminate is $2 \mathrm{~h}$. The thickness of the $\mathrm{i}^{\text {th }}$ ply is also specified by $\mathrm{h}_{\mathrm{i}}=\mathrm{Z}_{\mathrm{i}}-\mathrm{Z}_{\mathrm{i}-1}$. The orientation of the $\mathrm{i}^{\text {th }}$ ply is demonstrated by the angle $\theta_{\mathrm{i}}$ (measured counter clockwise) between the loading and the fiber direction of the layer. The stress and strain components and also material properties associated with the $\mathrm{i}^{\text {th }}$ layer are denoted by a superscript or subscript i. It is assumed that the laminate is long (see Fig. 1) and can be infinitely extended in $\mathrm{x}$ directions $(\mathrm{L}>>\mathrm{W})$ where $2 \mathrm{~L}$ and $2 \mathrm{~W}$ are, respectively, the length and width of laminate.

The laminate is subject to external uniform strain $\varepsilon_{\mathrm{xx}}$ and a temperature difference $\Delta \mathrm{T}$. In a long

and wide laminate without any free edges, the only nonzero stress terms are $\sigma_{\mathrm{xx}}^{0(\mathrm{i})}, \sigma_{\mathrm{yy}}^{0(\mathrm{i})}, \sigma_{\mathrm{xy}}^{0(\mathrm{i})}$, where the superscript 0 defines the infinite or unperturbed laminate (without free edge) and the 
superscript (i), $i=1,2, \ldots, N$, specifies the number of the ply. In this paper, the terms "infinite laminate" or "unperturbed laminate" refer to a long and wide laminate which does not have any free edges. Following the methodology used by Hashin [14] for analysis of cracked laminates, the stresses in the final geometry (with free edges) can be written as a superposition of the stresses in the unperturbed state and some perturbation stress functions (yet unknown) appeared due to the presence of the free edges.

$$
\sigma_{\mathrm{mn}}^{\mathrm{i}}(\mathrm{X})=\sigma_{\mathrm{mn}}^{0(\mathrm{i})}+\sigma_{\mathrm{mn}}^{\mathrm{p}(\mathrm{i})}(\mathrm{X}) .
$$

where $\mathrm{m}, \mathrm{n}=\mathrm{x}, \mathrm{y}, \mathrm{z}$ and $\mathrm{X}=\mathrm{y}, \mathrm{z}$. The first term in the right hand of Eq. (1) is the stress in the $\mathrm{i}^{\text {th }}$ ply of the infinite laminate, which can be determined using an analysis based on the classical laminated plat theory. The second term in right hand of Eq. (1) is the perturbation stress in the $\mathrm{i}^{\text {th }}$ ply, which unlike the stresses in the infinite laminate, is a function of location (X).

We aim to find admissible stress and displacement fields that satisfy the stress equilibrium equations $\sigma_{\mathrm{mn}, \mathrm{n}}^{\mathrm{i}}(\mathrm{X})=0$ and the following stress-strain-temperature relations:

$$
\begin{aligned}
& \varepsilon_{\mathrm{xx}}^{\mathrm{i}} \equiv \frac{\partial \mathrm{u}_{\mathrm{i}}}{\partial \mathrm{x}}=\mathrm{S}_{11}^{\mathrm{i}} \sigma_{\mathrm{xx}}^{\mathrm{i}}+\mathrm{S}_{12}^{\mathrm{i}} \sigma_{\mathrm{yy}}^{\mathrm{i}}+\mathrm{S}_{13}^{\mathrm{i}} \sigma_{\mathrm{zz}}^{\mathrm{i}}+\mathrm{S}_{16}^{\mathrm{i}} \sigma_{\mathrm{xy}}^{\mathrm{i}}+\alpha_{1}^{\mathrm{i}} \Delta \mathrm{T}, \\
& \varepsilon_{y y}^{i} \equiv \frac{\partial v_{i}}{\partial y}=S_{12}^{i} \sigma_{x x}^{i}+S_{22}^{i} \sigma_{y y}^{i}+S_{23}^{i} \sigma_{z z}^{i}+S_{26}^{i} \sigma_{x y}^{i}+\alpha_{2}^{i} \Delta T, \\
& \varepsilon_{z z}^{\mathrm{i}} \equiv \frac{\partial \mathrm{w}_{\mathrm{i}}}{\partial \mathrm{x}}=\mathrm{S}_{13}^{\mathrm{i}} \sigma_{\mathrm{xx}}^{\mathrm{i}}+\mathrm{S}_{23}^{\mathrm{i}} \sigma_{\mathrm{yy}}^{\mathrm{i}}+\mathrm{S}_{33}^{\mathrm{i}} \sigma_{\mathrm{zz}}^{\mathrm{i}}+\mathrm{S}_{36}^{\mathrm{i}} \sigma_{\mathrm{xy}}^{\mathrm{i}}+\alpha_{3}^{\mathrm{i}} \Delta \mathrm{T}, \\
& 2 \varepsilon_{\mathrm{yz}}^{\mathrm{i}} \equiv \frac{\partial \mathrm{v}_{\mathrm{i}}}{\partial \mathrm{z}}+\frac{\partial \mathrm{w}_{\mathrm{i}}}{\partial \mathrm{y}}=\mathrm{S}_{44}^{\mathrm{i}} \sigma_{\mathrm{yz}}^{\mathrm{i}}+\mathrm{S}_{45}^{\mathrm{i}} \sigma_{\mathrm{xz}}^{\mathrm{i}} \\
& 2 \varepsilon_{\mathrm{xz}}^{\mathrm{i}} \equiv \frac{\partial \mathrm{u}_{\mathrm{i}}}{\partial \mathrm{z}}+\frac{\partial \mathrm{w}_{\mathrm{i}}}{\partial \mathrm{x}}=\mathrm{S}_{45}^{\mathrm{i}} \sigma_{\mathrm{yz}}^{\mathrm{i}}+\mathrm{S}_{55}^{\mathrm{i}} \sigma_{\mathrm{xz}}^{\mathrm{i}} \\
& 2 \varepsilon_{\mathrm{xy}}^{\mathrm{i}} \equiv \frac{\partial \mathrm{u}_{\mathrm{i}}}{\partial \mathrm{y}}+\frac{\partial \mathrm{v}_{\mathrm{i}}}{\partial \mathrm{x}}=\mathrm{S}_{16}^{\mathrm{i}} \sigma_{\mathrm{xx}}^{\mathrm{i}}+\mathrm{S}_{26}^{\mathrm{i}} \sigma_{\mathrm{yy}}^{\mathrm{i}}+\mathrm{S}_{36}^{\mathrm{i}} \sigma_{\mathrm{zz}}^{\mathrm{i}}+\mathrm{S}_{66}^{\mathrm{i}} \sigma_{\mathrm{xy}}^{\mathrm{i}}+\alpha_{6}^{\mathrm{i}} \Delta \mathrm{T},
\end{aligned}
$$


where $u_{i}, v_{i}$ and $w_{i}$ define components of the displacement field for the $i^{\text {th }}$ layer in the $x, y$ and $z$ directions, respectively, and $\varepsilon_{\mathrm{xx}}^{\mathrm{i}}$, $\varepsilon_{\mathrm{yy}}^{\mathrm{i}}$ etc., represent the infinitesimal strain terms. Moreover, the constants $S_{i j}$ and $\alpha_{i}$, respectively, show the compliance and thermal expansion coefficients of the $\mathrm{i}^{\text {th }}$ layer. In addition, the admissible stress and displacement fields must satisfy the following boundary and interface continuity conditions:

1. Traction free condition on the top external surfaces $\mathrm{z}=\mathrm{h}: \sigma_{\mathrm{xz}}^{\mathrm{N}}=\sigma_{\mathrm{yz}}^{\mathrm{N}}=\sigma_{\mathrm{zz}}^{\mathrm{N}}=0$.

2. Zero out-of-plane shear stresses $\sigma_{\mathrm{xz}}$ and $\sigma_{\mathrm{yz}}$ at the mid-plane $\mathrm{z}=0$ (due to symmetry with respect to the mid-plane).

3. Stress and displacement continuity conditions at the location of interfaces between the plies $\left(\mathrm{z}=\mathrm{Z}_{\mathrm{i}}, \mathrm{i}=1,2, \ldots, \mathrm{N}-1\right): \sigma_{\mathrm{xz}}^{\mathrm{i}}=\sigma_{\mathrm{xz}}^{\mathrm{i}+1}, \sigma_{\mathrm{yz}}^{\mathrm{i}}=\sigma_{\mathrm{yz}}^{\mathrm{i}+1}, \sigma_{\mathrm{zz}}^{\mathrm{i}}=\sigma_{\mathrm{zz}}^{\mathrm{i}+1}$ and $\mathrm{u}_{\mathrm{i}}=\mathrm{u}_{\mathrm{i}+1}, \mathrm{v}_{\mathrm{i}}=\mathrm{v}_{\mathrm{i}+1}, \mathrm{w}_{\mathrm{i}}=\mathrm{w}_{\mathrm{i}+1}$.

4. Traction free condition on the free edges at $y= \pm W, i=1,2, \ldots, N-1: \sigma_{y y}^{i}=\sigma_{x y}^{i}=\sigma_{y z}^{i}=0$.

\subsection{Admissible stress field construction}

It is noted that in the considered coordinate system where the free edges are parallel to the $\mathrm{x}$-axis, the stress terms are independent of the axial direction because the laminate is long $(\mathrm{L}>>\mathrm{w})$. Moreover, we assume that the in-plane transverse and shear perturbation stresses in each ply vary only along the y direction, perpendicular to the free edge planes, and can be written as:

$$
\sigma_{y y}^{p(i)}(y)=-p_{i}(y) / h_{i}, \quad \sigma_{x y}^{p(i)}(y)=-q_{i}(y) / h_{i}
$$

where $\mathrm{p}_{\mathrm{i}}$ and $\mathrm{q}_{\mathrm{i}}$ are unknown functions of the y coordinate. Using these assumed forms (Eq. (8)), the other stress components are derived by satisfying the equations of equilibrium. Solving the equilibrium equations leads to the condition that the transverse shear $\left(\sigma_{x z}^{p(i)}, \sigma_{y z}^{p(i)}\right)$ and transverse normal stresses $\left(\sigma_{\mathrm{zz}}^{\mathrm{p}(\mathrm{i})}\right)$, respectively, are linear and quadratic functions of $\mathrm{z}$ in each layer: 


$$
\begin{gathered}
\sigma_{y z}^{p(i)}(y, z)=p^{\prime}{ }_{i}(y)\left(z-z_{i}\right) / h_{i}+\sum_{j=1}^{i} p_{j}^{\prime}(y), \\
\sigma_{x z}^{p(i)}(y, z)=q^{\prime}{ }_{i}(y)\left(z-z_{i}\right) / h_{i}+\sum_{j=1}^{i} q_{j}^{\prime}(y), \\
\sigma_{z z}^{p(i)}(y, z)=-p^{\prime \prime}{ }_{i}(y)\left(z-z_{i}\right)^{2} / 2 h_{i}-z \sum_{j=1}^{i} p^{\prime \prime}{ }_{j}(y)-\frac{1}{2} \sum_{j=i+1}^{N}\left(z_{j}+z_{j-1}\right) p^{\prime \prime}{ }_{j}(y) .
\end{gathered}
$$

It should be noted that to obtain equations (9)-(11), use has been made of integrating stress equilibrium equations $\sigma_{\mathrm{mn}, \mathrm{n}}^{\mathrm{i}}(\mathrm{X})=0$, together with satisfying stress continuity conditions at the interface between plies.

The in-plane axial strain $\left(\varepsilon_{\mathrm{xx}}\right)$ is one of the input loading parameters and thus has a uniform value in all layers of the laminate. Therefore, using Eq. (2), the perturbation in-plane axial stress can be defined in terms of the other perturbation stress terms, as follows:

$$
\begin{gathered}
\sigma_{x x}^{\mathrm{i}}=\sigma_{\mathrm{xx}}^{0(\mathrm{i})}+\sigma_{\mathrm{xx}}^{\mathrm{p}(\mathrm{i})}=\left(\varepsilon_{\mathrm{xx}}-\mathrm{S}_{12}^{\mathrm{i}} \sigma_{\mathrm{yy}}^{\mathrm{i}}-\mathrm{S}_{13}^{\mathrm{i}} \sigma_{\mathrm{zz}}^{\mathrm{i}}-\mathrm{S}_{16}^{\mathrm{i}} \sigma_{\mathrm{xy}}^{\mathrm{i}}-\alpha_{1}^{\mathrm{i}} \Delta \mathrm{T}\right) / \mathrm{S}_{11}^{\mathrm{i}}, \\
\sigma_{\mathrm{xx}}^{0(\mathrm{i})}=\left(\varepsilon_{\mathrm{xx}}-\mathrm{S}_{12}^{\mathrm{i}} \sigma_{\mathrm{yy}}^{0(\mathrm{i})}-\mathrm{S}_{16}^{\mathrm{i}} \sigma_{\mathrm{xy}}^{0(\mathrm{i})}-\alpha_{1}^{\mathrm{i}} \Delta \mathrm{T}\right) / \mathrm{S}_{11}^{\mathrm{i}}, \\
\sigma_{\mathrm{xx}}^{\mathrm{p}(\mathrm{i})}(\mathrm{y}, \mathrm{z})=\left(-\mathrm{S}_{12}^{\mathrm{i}} \sigma_{\mathrm{yy}}^{\mathrm{p}(\mathrm{i})}-\mathrm{S}_{13}^{\mathrm{i}} \sigma_{\mathrm{zz}}^{\mathrm{p}(\mathrm{i})}-\mathrm{S}_{16}^{\mathrm{i}} \sigma_{\mathrm{xy}}^{\mathrm{p}(\mathrm{i})}\right) / \mathrm{S}_{11}^{\mathrm{i}},
\end{gathered}
$$

The admissible perturbation stress field should satisfy the traction boundary conditions $\mathrm{N}_{\mathrm{yy}}=0$ and $\mathrm{N}_{\mathrm{xy}}=0$. This asserts that the following relations between perturbation functions must be satisfied:

$$
\sum_{\mathrm{i}=1}^{\mathrm{N}} \mathrm{p}_{\mathrm{i}}(\mathrm{y})=0, \quad \sum_{\mathrm{i}=1}^{\mathrm{N}} \mathrm{q}_{\mathrm{i}}(\mathrm{y})=0 .
$$

It then follows that the out-of-plane shear stresses $\sigma_{\mathrm{xz}}$ and $\sigma_{\mathrm{yz}}$ are automatically zero on $\mathrm{z}=0$ (due to symmetry with respect to the mid-plane). Moreover, the out-of-plane shear $\sigma_{\mathrm{xz}}, \sigma_{\mathrm{yz}}$ and normal $\sigma_{\mathrm{zz}}$ perturbation stresses are automatically zero on $\mathrm{z}= \pm \mathrm{h}$. 
The representation of the admissible stress field defined by equations (8)-(11) and (13) satisfies all equilibrium stress equations, through-thickness traction boundary conditions and interface continuity conditions for any perturbation functions $\mathrm{p}_{\mathrm{i}}(\mathrm{y})$ and $\mathrm{q}_{\mathrm{i}}(\mathrm{y}), \mathrm{i}=1 \ldots \mathrm{N}$, characterizing stress transfer mechanism in any symmetric laminate. Moreover, Eq. (14) provides two additional interrelationships between the perturbation stress functions to balance the applied traction boundary conditions of the laminate. Therefore, the total number of unknown perturbation stress functions that need to be obtained, is $2(\mathrm{~N}-1)$.

\subsection{Governing differential equations}

In this section, the most optimal functions will be evaluated that minimize the complementary energy. By partitioning the total stresses into unperturbed and perturbation stresses, the total complementary energy $\mathrm{U}_{\text {com }}$ of a laminate subject to displacement boundary condition and thermal residual stresses can be simplified as follows [22]:

$$
\mathrm{U}_{\mathrm{com}}=\mathrm{U}_{\mathrm{com}}^{0}+\mathrm{U}^{\mathrm{p}}, \quad \text { where } \mathrm{U}^{\mathrm{p}}=\frac{1}{2} \int_{\mathrm{V}} \sigma^{p^{T}} \mathrm{~s} \sigma^{p} \mathrm{dV}
$$

where $\mathrm{U}_{\text {com }}^{0}$ is the complementary energy of the laminate without free edges, which does not contribute to the variation. Moreover, $s$ is the compliance tensor and $V$ denotes region of the considered laminate.

For a laminate with free edges, we will minimize the perturbation complementary energy functional $\left(\mathrm{U}^{\mathrm{p}}\right)$ over the volume of width $2 W$ bounded by two free edges, such that $|\mathrm{y}| \leq$ $\mathrm{W}$ and $|\mathrm{z}| \leq \mathrm{h}$. As the laminate is symmetric, only the upper part $0 \leq z \leq h$ will be considered. Consequently:

$$
U^{p}=2 \sum_{i=1}^{N}\left(\int_{-W}^{W} \int_{z_{i-1}}^{z_{i}} \frac{1}{2}\left\{\sigma^{p(i)}\right\}^{T}\left[S^{(i)}\right]\left\{\sigma^{p(i)}\right\} d z d y\right),
$$


where $\left[S^{(i)}\right]$ is the compliance tensor of layer (i). Substituting the equations for the perturbation stress terms (Eqs. (8)-(13)) in Eq. (16) and using the rotated compliance matrices, it is possible to perform the integration over $\mathrm{z}$. It should be mentioned that unknown perturbation functions are not independent. Indeed, one out of any $\mathrm{N}$ unknowns of $\mathrm{p}_{\mathrm{i}}$ and $\mathrm{q}_{\mathrm{i}}, \mathrm{i}=1,2, \ldots \mathrm{N}$, can be eliminated using Eq. (14). Therefore, the result of integration over $\mathrm{z}$ in (16) would be written in the following form, based on the independent unknown perturbation functions:

$$
\begin{gathered}
\mathrm{U}^{\mathrm{p}}=\int_{-\mathrm{W}}^{\mathrm{W}} \mathrm{F}\left(\mathrm{y},\{\mathrm{p}\},\left\{\mathrm{p}^{\prime}\right\},\left\{\mathrm{p}^{\prime \prime}\right\},\{\mathrm{q}\},\left\{\mathrm{q}^{\prime}\right\}\right) d y, \text { where } \\
\mathrm{F}\left(\mathrm{y},\{\mathrm{p}\},\left\{\mathrm{p}^{\prime}\right\},\left\{\mathrm{p}^{\prime \prime}\right\},\{\mathrm{q}\},\left\{\mathrm{q}^{\prime}\right\}\right)=\{\mathrm{p}\}^{\mathrm{T}}\left[\mathrm{A}_{11}^{00}\right]\{\mathrm{p}\}+\{\mathrm{q}\}^{\mathrm{T}}\left[\mathrm{A}_{22}^{00}\right]\{\mathrm{q}\}+\{\mathrm{p}\}^{\mathrm{T}}\left[\mathrm{A}_{12}^{00}\right]\{\mathrm{q}\}+\left\{\mathrm{p}^{\prime}\right\}^{\mathrm{T}}\left[\mathrm{A}_{11}^{11}\right]\left\{\mathrm{p}^{\prime}\right\} \\
+\left\{\mathrm{q}^{\prime}\right\}^{\mathrm{T}}\left[\mathrm{A}_{22}^{11}\right]\left\{\mathrm{q}^{\prime}\right\}+\left\{\mathrm{p}^{\prime}\right\}^{\mathrm{T}}\left[\mathrm{A}_{12}^{11}\right]\left\{\mathrm{q}^{\prime}\right\}+\left\{\mathrm{p}^{\prime \prime}\right\}^{\mathrm{T}}\left[\mathrm{A}_{11}^{20}\right]\{\mathrm{p}\}+\left\{\mathrm{p}^{\prime \prime}\right\}^{\mathrm{T}}\left[\mathrm{A}_{12}^{20}\right]\{\mathrm{q}\}+\left\{\mathrm{p}^{\prime \prime}\right\}^{\mathrm{T}}\left[\mathrm{A}_{11}^{22}\right]\left\{\mathrm{p}^{\prime \prime}\right\}
\end{gathered}
$$

where $\{p\}$ and $\{q\}$ are vectors of independent unknown perturbation functions and the coefficient matrices $\left[A_{11}^{00}\right]$, etc., can be easily evaluated analytically in terms of ply properties.

The independent unknown perturbation functions $\{p\}$ and $\{q\}$ will be evaluated from the minimization of the perturbation complementary energy functional. It is well understood that taking a variation from the complementary energy functional leads to the Euler-Lagrange equations [15-18]. For the complementary energy functional defined in Eq. (17), the EulerLagrange equations as the governing equations of the problem have the following forms:

$$
\begin{gathered}
\frac{\partial \mathrm{F}}{\partial\{\mathrm{p}\}}-\frac{\mathrm{d}}{\mathrm{dy}}\left(\frac{\partial \mathrm{F}}{\partial\left\{\mathrm{p}^{\prime}\right\}}\right)+\frac{\mathrm{d}^{2}}{\mathrm{dy}^{2}}\left(\frac{\partial \mathrm{F}}{\partial\left\{\mathrm{p}^{\prime \prime}\right\}}\right)=0, \\
\frac{\partial \mathrm{F}}{\partial\{\mathrm{q}\}}-\frac{\mathrm{d}}{\mathrm{dy}}\left(\frac{\partial \mathrm{F}}{\partial\left\{\mathrm{q}^{\prime}\right\}}\right)=0 .
\end{gathered}
$$

Considering the functional (F) defined in Eqs. (17) and (18), the above Euler-Lagrange equations can be written as follows:

$$
\left[\mathrm{T}_{1}\right]\left\{\mathrm{p}^{\prime \prime \prime \prime}\right\}+\left[\mathrm{T}_{2}\right]\left\{\mathrm{p}^{\prime \prime}\right\}+\left[\mathrm{T}_{3}\right]\{\mathrm{p}\}+\left[\mathrm{T}_{4}\right]\left\{\mathrm{q}^{\prime \prime}\right\}+\left[\mathrm{T}_{5}\right]\{\mathrm{q}\}=0
$$




$$
\left[\mathrm{T}_{4}\right]^{\mathrm{T}}\left\{\mathrm{p}^{\prime \prime \prime \prime}\right\}+\left[\mathrm{T}_{5}\right]^{\mathrm{T}}\left\{\mathrm{p}^{\prime \prime}\right\}+\left[\mathrm{T}_{6}\right]\left\{\mathrm{q}^{\prime \prime}\right\}+\left[\mathrm{T}_{7}\right]\{\mathrm{q}\}=0
$$

where

$$
\begin{aligned}
& {\left[\mathrm{T}_{1}\right]=\left[\mathrm{A}_{11}^{22}\right]+\left[\mathrm{A}_{11}^{22}\right]^{\mathrm{T}}, \quad\left[\mathrm{T}_{2}\right]=\left[\mathrm{A}_{11}^{20}\right]+\left[\mathrm{A}_{11}^{20}\right]^{\mathrm{T}}-\left[\mathrm{A}_{11}^{11}\right]-\left[\mathrm{A}_{11}^{11}\right]^{\mathrm{T}}, \quad\left[\mathrm{T}_{3}\right]=\left[\mathrm{A}_{11}^{00}\right]+\left[\mathrm{A}_{11}^{00}\right]^{\mathrm{T}},} \\
& {\left[\mathrm{T}_{4}\right]=-\left[\mathrm{A}_{12}^{11}\right]+\left[\mathrm{A}_{12}^{20}\right], \quad\left[\mathrm{T}_{5}\right]=\left[\mathrm{A}_{12}^{00}\right], \quad\left[\mathrm{T}_{6}\right]=-\left[\mathrm{A}_{22}^{11}\right]-\left[\mathrm{A}_{22}^{11}\right]^{\mathrm{T}}, \quad\left[\mathrm{T}_{7}\right]=\left[\mathrm{A}_{22}^{00}\right]+\left[\mathrm{A}_{22}^{00}\right]^{\mathrm{T}}}
\end{aligned}
$$

It can be clearly seen that the Eqs. (21) and (22) are a coupled systems of homogeneous ordinary differential equations with constant coefficients. There are many methods to analytically solve these differential equations. The reader is referred to Ref. [15] to find details about solving these differential equations. Moreover, it is noted that the coupled system in Equations (21) and (22) is very similar to the equations which has been derived by McCartney [23] using a stress transfer model for general symmetric laminates containing ply cracks. The method of numerically solving the system of differential equations (21) and (22) is described by Hannaby [24]. The reader should also refer to these publications $[23,24]$ for more details.

Having the general solution for these differential equations (Eqs. (21) and (22)), the final step is determining arbitrary constants of the solution implementing the traction boundary conditions at free edges. These coupled systems (Eqs. (21) and (22)) require 6(N-1) boundary conditions.

The traction free conditions for each layer on the free edges $\mathrm{y}= \pm \mathrm{W}$, can be written

$$
\sigma_{\mathrm{yy}}^{\mathrm{i}}(y= \pm W)=0, \quad \sigma_{\mathrm{xy}}^{\mathrm{i}}(y= \pm W)=0, \quad \sigma_{\mathrm{yz}}^{\mathrm{i}}(y= \pm W)=0 .
$$

The above equation can be simplified in terms of the perturbation functions:

$$
p_{i}(y= \pm W)=\sigma_{y y}^{0(i)} h_{i}, \quad q_{i}(y= \pm W)=\sigma_{x y}^{0(i)} h_{i}, \quad p_{i}^{\prime}(y= \pm W)=0 .
$$

There are clearly $6(\mathrm{~N}-1)$ of these traction free boundary conditions, as needed.

It is noted that by partitioning the stress field for a laminate with free edges into unperturbed (solution of classical laminated plate theory) and perturbation stresses (due to the presence of free 
edges), the effects of the actual mechanical and thermal loads come through these constant fields in the boundary conditions at free surfaces.

\subsection{Displacement fields}

As shown in the previous sections, the variational model needs only stress components. Indeed, in order to determine the solution, the variational approach makes use of the minimum complementary energy principle, which does not require corresponding displacement fields. However, it has been shown by Rosen [25] that of all stress fields which satisfy equilibrium throughout the region and boundary conditions on portions of the surface over which tractions are prescribed, the set that yields a compatible set of displacements minimizes the complementary energy. In this section, following the approach developed by McCartney [26] for stress transfer in cracked laminates, an attempt is made to derive corresponding displacement fields for the variational model based on the admissible stress fields (Eq. (8)-(11)).

The laminate is assumed to be under generalized in-plane strain conditions for which the displacement field in each layer (i) of the laminate is of the following form

$$
\mathrm{u}_{\mathrm{i}}=\mathrm{f}_{1}^{\mathrm{i}}(\mathrm{y}, \mathrm{z})+\varepsilon_{\mathrm{xx}} \mathrm{x}+\varepsilon_{\mathrm{xy}}^{0} \mathrm{y}, \quad \mathrm{v}_{\mathrm{i}}=\mathrm{f}_{2}^{\mathrm{i}}(\mathrm{y}, \mathrm{z})+\varepsilon_{\mathrm{yy}}^{0} \mathrm{y}+\varepsilon_{\mathrm{xy}}^{0} \mathrm{x}, \quad \mathrm{w}_{\mathrm{i}}=\mathrm{f}_{3}^{\mathrm{i}}(\mathrm{y}, \mathrm{z}),
$$

where $\varepsilon_{\mathrm{yy}}^{0}$ and $2 \varepsilon_{\mathrm{xy}}^{0}$ are the transverse and shear strains in the infinite laminate (without free edge) when the laminate is under the uniform axial strain $\varepsilon_{\mathrm{xx}}$ and a temperature difference $\Delta \mathrm{T}$.

It is noted that the functions $\mathrm{f}_{\mathrm{k}}^{\mathrm{i}}, \mathrm{k}=1,2,3, \mathrm{i}=1 \ldots \mathrm{N}$, that are to be determined, are all independent of $\mathrm{x}$. These functions are identically zero for the infinite laminate (without free edge). It is evident that the assumed displacement field (Eq. (26) 1 ) satisfies Eq. (2) automatically, because of the relations (12) and (13).

It follows from Eqs. (4), (8), (11) and (12) that, for $\mathrm{z}_{\mathrm{i}-1}<\mathrm{z} \leq \mathrm{z}_{\mathrm{i}}$ and $\mathrm{i}=1 \ldots \mathrm{N}$, 


$$
\begin{gathered}
\mathrm{w}_{\mathrm{i}}=-\frac{\left(\mathrm{S}_{33}^{\mathrm{i}}-\mathrm{S}_{13}^{\mathrm{i}}{ }^{2} / \mathrm{S}_{11}^{\mathrm{i}}\right)\left(\mathrm{z}-\mathrm{z}_{\mathrm{i}}\right)^{2}}{2 \mathrm{~h}_{\mathrm{i}}}\left[\frac{\left(\mathrm{z}-\mathrm{z}_{\mathrm{i}}\right)}{3} \mathrm{p}^{\prime \prime}{ }_{\mathrm{i}}(\mathrm{y})+\mathrm{h}_{\mathrm{i}} \sum_{\mathrm{j}=1}^{\mathrm{i}} \mathrm{p}^{\prime \prime}{ }_{\mathrm{j}}(\mathrm{y})\right] \\
-\left(\mathrm{S}_{33}^{\mathrm{i}}-\mathrm{S}_{13}^{\mathrm{i}}{ }^{2} / \mathrm{S}_{11}^{\mathrm{i}}\right)\left(\mathrm{z}-\mathrm{z}_{\mathrm{i}}\right)\left[\frac{1}{2} \sum_{\mathrm{j}=1+\mathrm{i}}^{\mathrm{N}}\left(\mathrm{z}_{\mathrm{j}}+\mathrm{z}_{\mathrm{j}-1}\right) \mathrm{p}^{\prime \prime}{ }_{\mathrm{j}}(\mathrm{y})+\mathrm{z}_{\mathrm{i}} \sum_{\mathrm{j}=1}^{\mathrm{i}} \mathrm{p}^{\prime \prime}{ }_{\mathrm{j}}(\mathrm{y})\right] \\
+\left(\mathrm{z}-\mathrm{z}_{\mathrm{i}}\right)\left[\varepsilon_{\mathrm{zz}}^{0(\mathrm{i})}-\frac{\left(\mathrm{S}_{23}^{\mathrm{i}}-\mathrm{S}_{{ }_{13}}^{\mathrm{i}}{ }_{12}^{\mathrm{i}} / \mathrm{S}_{11}^{\mathrm{i}}\right) \mathrm{p}_{\mathrm{i}}(\mathrm{y})}{\mathrm{h}_{\mathrm{i}}}-\frac{\left(\mathrm{S}_{36}^{\mathrm{i}}-\mathrm{S}_{13}^{\mathrm{i}} \mathrm{S}_{16}^{\mathrm{i}} / \mathrm{S}_{11}^{\mathrm{i}}\right) \mathrm{q}_{\mathrm{i}}(\mathrm{y})}{\mathrm{h}_{\mathrm{i}}}\right]+\mathrm{W}_{\mathrm{i}}(\mathrm{y}) .
\end{gathered}
$$

In the above equation, $\mathrm{W}_{\mathrm{i}}(\mathrm{y})$ which arises from the integration over $\mathrm{z}$, is the out-of-plane displacement (to be defined later) at the interface $\mathrm{z}=\mathrm{z}_{\mathrm{i}}$. Moreover, $\varepsilon_{\mathrm{zz}}^{0(\mathrm{i})}$ is the out-of-plane axial strain in the $\mathrm{i}^{\text {th }}$ ply of a symmetric laminate without free edges.

It follows from Eq. (5), (9)-(13) and (27) that, for $z_{i-1}<z \leq z_{i}$ and $i=1 \ldots N$,

$$
\begin{gathered}
\mathrm{v}_{\mathrm{i}}=\left(\mathrm{S}_{33}^{\mathrm{i}}-\frac{\mathrm{S}_{13}^{\mathrm{i}}{ }^{2}}{\mathrm{~S}_{11}^{\mathrm{i}}}\right)\left(\mathrm{z}-\mathrm{z}_{\mathrm{i}}\right)^{3}\left[\frac{\left(\mathrm{z}-\mathrm{z}_{\mathrm{i}}\right)}{24 \mathrm{~h}_{\mathrm{i}}} \mathrm{p}^{\prime \prime \prime}{ }_{\mathrm{i}}(\mathrm{y})+\frac{1}{6} \sum_{\mathrm{j}=1}^{\mathrm{i}} \mathrm{p}^{\prime \prime \prime}{ }_{\mathrm{j}}(\mathrm{y})\right] \\
+\left(\mathrm{S}_{33}^{\mathrm{i}}-\frac{\mathrm{S}_{13}^{\mathrm{i}}{ }^{2}}{\mathrm{~S}_{11}^{\mathrm{i}}}\right)\left(\mathrm{z}-\mathrm{z}_{\mathrm{i}}\right)^{2}\left[\frac{1}{4} \sum_{\mathrm{j}=1+\mathrm{i}}^{\mathrm{N}}\left(\mathrm{z}_{\mathrm{j}}+\mathrm{z}_{\mathrm{j}-1}\right) \mathrm{p}^{\prime \prime \prime}{ }_{\mathrm{j}}(\mathrm{y})+\frac{1}{2} \mathrm{z}_{\mathrm{i}} \sum_{\mathrm{j}=1}^{\mathrm{i}} \mathrm{p}^{\prime \prime \prime}{ }_{\mathrm{j}}(\mathrm{y})\right] \\
+\frac{\left(\mathrm{z}-\mathrm{z}_{\mathrm{i}}\right)^{2}}{2 \mathrm{~h}_{\mathrm{i}}}\left[\mathrm{S}_{44}^{\mathrm{i}} \mathrm{p}_{\mathrm{i}}{ }_{\mathrm{i}}(\mathrm{y})+\mathrm{S}_{45}^{\mathrm{i}} \mathrm{q}_{\mathrm{i}}^{\prime}(\mathrm{y})+\left(\mathrm{S}_{23}^{\mathrm{i}}-\frac{\mathrm{S}_{13}^{\mathrm{i}} \mathrm{S}_{12}^{\mathrm{i}}}{\mathrm{S}_{11}^{\mathrm{i}}}\right) \mathrm{p}_{\mathrm{i}}{ }_{\mathrm{i}}(\mathrm{y})+\left(\mathrm{S}_{36}^{\mathrm{i}}-\frac{\mathrm{S}_{13}^{\mathrm{i}} \mathrm{S}_{16}^{\mathrm{i}}}{\mathrm{S}_{11}^{\mathrm{i}}}\right) \mathrm{q}_{\mathrm{i}}^{\prime}(\mathrm{y})\right] \\
+\left(\mathrm{z}-\mathrm{z}_{\mathrm{i}}\right)\left[\mathrm{S}_{44}^{\mathrm{i}} \sum_{\mathrm{j}=1}^{\mathrm{i}} \mathrm{p}_{\mathrm{j}}^{\prime}(\mathrm{y})+\mathrm{S}_{45}^{\mathrm{i}} \sum_{\mathrm{j}=1}^{\mathrm{i}} \mathrm{q}_{\mathrm{j}}{ }_{\mathrm{j}}(\mathrm{y})\right]-\left(\mathrm{z}-\mathrm{z}_{\mathrm{i}}\right) \mathrm{W}_{\mathrm{i}}^{\prime}(\mathrm{y})+\mathrm{V}_{\mathrm{i}}(\mathrm{x}, \mathrm{y}),
\end{gathered}
$$

where $\mathrm{V}_{\mathrm{i}}(\mathrm{x}, \mathrm{y})$, arising from the integration over $\mathrm{z}$, is the in-plane transverse displacement at $\mathrm{z}=\mathrm{Z}_{\mathrm{i}}$. Similarly from Eq. (6), (9)-(13) and (27) that, for $z_{i-1}<z \leq z_{i}$ and $i=1 \ldots N$,

$$
\begin{aligned}
u_{i} & =\left(z-z_{i}\right) S_{45}^{i}\left[\frac{\left(z-z_{i}\right)}{2 h_{i}} p_{i}^{\prime}(y)+\sum_{j=1}^{i} p_{j}^{\prime}(y)\right] \\
& +\left(z-z_{i}\right) S_{55}^{i}\left[\frac{\left(z-z_{i}\right)}{2 h_{i}} q_{i}^{\prime}(y)+\sum_{j=1}^{i} q_{j}^{\prime}(y)\right]+U_{i}(x, y),
\end{aligned}
$$


where $U_{i}(x, y)$, arising from the integration over $\mathrm{z}$, is the in-plane axial displacement at $\mathrm{z}=\mathrm{Z}_{\mathrm{i}}$. The functions $\mathrm{W}_{\mathrm{i}}(\mathrm{y}), \mathrm{V}_{\mathrm{i}}(\mathrm{x}, \mathrm{y})$ and $\mathrm{U}_{\mathrm{i}}(\mathrm{x}, \mathrm{y}), \mathrm{i}=1 \ldots \mathrm{N}$, will be defined in terms of the perturbation functions $\mathrm{p}_{\mathrm{i}}(\mathrm{y}), \mathrm{q}_{\mathrm{i}}(\mathrm{y})$, by three recurrence relations, as presented in Appendix.

\section{Results and Discussion}

In order to validate the developed methodology and the associated software implementation, the results predicted by the present model are compared with the well-known 3D finite element results of Wang and Crossman $[20,21]$ for $[0 / 90]_{\mathrm{s}},[45 /-45]_{\mathrm{s}}$ and $[45 /-45 / 90 / 0]_{\mathrm{s}}$ laminates. The following material and geometrical properties are used for this investigation [20, 21]:

$$
\begin{aligned}
& E_{\mathrm{A}}=137.9 \mathrm{GPa}, \quad \mathrm{E}_{\mathrm{T}}=14.48 \mathrm{GPa}, \quad \mathrm{G}_{\mathrm{A}}=\mathrm{G}_{\mathrm{T}}=5.86 \mathrm{GPa}, \quad \mathrm{t}_{\mathrm{ply}}=0.19 \mathrm{~mm} \\
& v_{\mathrm{A}}=v_{\mathrm{T}}=0.21, \quad \alpha_{\mathrm{A}}=0.36 \times 10^{-6}{ }^{0} \mathrm{C}^{-1}, \quad \alpha_{\mathrm{T}}=28.8 \times 10^{-6}{ }^{0} \mathrm{C}^{-1}, \quad 2 \mathrm{~W}=16 \times \mathrm{t}_{\text {ply }}
\end{aligned}
$$

As mentioned earlier, the formulation is derived in a systematic way and thus, a software is

developed to deal with general symmetric laminates with arbitrary number of plies. It is possible to implement a ply refinement technique in order to improve the accuracy of predictions based on the variational approach. Thus, each ply is divided into 5 elements of equal thickness. Due to the high stress concentration at the interface between plies near free edges, it is useful to further subdivide the elements adjacent to both the interfaces so that the stress singularities can be resolved. The elements adjacent to both interfaces have been successively divided in fourth, three times. Figs. $2 \mathrm{a}$ and $2 \mathrm{~b}$ show, respectively, the transverse distribution of interlaminar normalized axial $\left(\sigma_{\mathrm{zz}} / \varepsilon_{\mathrm{xx}}\right)$ and shear $\left(\sigma_{\mathrm{yz}} / \varepsilon_{\mathrm{xx}}\right)$ stresses at the $0 / 90$ interface of a $[0 / 90]_{\mathrm{s}}$ laminate under uniform extension $\varepsilon_{\mathrm{xx}}$. Fig. 3a shows the transverse distribution of normalized transverse displacement ($\left.\mathrm{v} / \mathrm{t}_{\mathrm{ply}} / \varepsilon_{\mathrm{xx}}\right)$ at top surface $(\mathrm{z}=\mathrm{h})$ of the $[0 / 90]_{\mathrm{s}}$ laminate. Moreover, Fig. 3b shows through thickness distribution of the normalized transverse displacement $\left(-\mathrm{v} / \mathrm{t}_{\mathrm{ply}} / \varepsilon_{\mathrm{xx}}\right)$ at free edge $(\mathrm{y}=\mathrm{W})$ of the $[0 / 90]_{\mathrm{s}}$ laminate. Figs. $4 \mathrm{a}$ and $4 \mathrm{~b}$ also show, respectively, the transverse distribution of interlaminar 
normalized axial stresses $\left(\sigma_{\mathrm{zz}} / \varepsilon_{\mathrm{xx}}\right)$ at the mid-plane $(\mathrm{z}=0)$ and at the $0 / 90$ interface of a [45/-

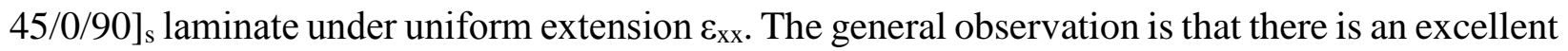
agreement between the results obtained from the current formulation and those of FEM [20] which verifies the accuracy of the developed method in predicting both stress and displacement fields near free edges of a symmetric laminate under uniaxial tension.

Figs. 5a and 5b show, respectively, the transverse distribution of interlaminar normalized axial $\left(\sigma_{\mathrm{zz}} / \Delta \mathrm{T}\right)$ and shear $\left(\sigma_{\mathrm{xz}} / \Delta \mathrm{T}\right)$ stresses at the $45 /-45$ interface of a [45/-45]s laminate under uniform thermal load $\Delta \mathrm{T}$. There is again an excellent agreement with FEM results [21] which verifies the accuracy of the derived stress-based variational model for thermal loading condition. However, these agreements are not very surprising as the derived analytical formulation is superior to FEM not only in terms of computational efficiency but also in terms of accuracy. It is noteworthy to mention that the assumed displacement and stress fields satisfy exactly stress equilibrium, straindisplacement relations and all the boundary and continuity conditions and also, the minimum complementary energy principle and a ply refinement technique are employed to approach the exact solution. The derived approach, when implemented together with a ply refinement technique, can be considered as a stress-based super element, where highly accurate result can be delivered and continuity of tractions and displacements at all element ply interfaces can be assured. Moreover, contrary to FEM (see Fig. 2b) which is generally a displacement-based approach, the derived stress fields exactly satisfy zero traction boundary conditions at free edges and upper and lower surfaces.

To further show the high computational efficiency and accuracy of the present model, the results obtained from the developed approach are compared with the refined 3D finite element results of 
Saeedi et. al [7], very close to the free edges for $[ \pm 10]_{s}$ and $[ \pm 20]_{s}$ laminates made of carbon/epoxy.

The following material and geometrical properties are used for this investigation [7]:

$$
\begin{array}{llll}
\text { CTE1/T700: } & \mathrm{E}_{\mathrm{A}}=153.82 \mathrm{GPa}, & \mathrm{E}_{\mathrm{T}}=10.61 \mathrm{GPa}, & \mathrm{G}_{\mathrm{A}}=\mathrm{G}_{\mathrm{T}}=5.58 \mathrm{GPa}, \\
& v_{\mathrm{A}}=v_{\mathrm{T}}=0.315, & \mathrm{t}_{\mathrm{ply}}=0.13 \mathrm{~mm}, & 2 \mathrm{~W}=20 \mathrm{~mm} .
\end{array}
$$

Figs. 6 shows across the width distribution of the normalized interlaminar shear $\left(\sigma_{\mathrm{x} z} / \mathrm{E}_{\mathrm{xx}} / \varepsilon_{\mathrm{xx}}\right)$ stresses at the $-\theta / \theta$ interface of $[ \pm \theta]_{s}$ laminates $\left(\theta=10^{0}, 20^{0}\right)$ under uniform extension $\varepsilon_{x x}$. It is noted that $E_{x x}$ is the axial stiffness of the laminate. It should be mentioned that the finite element mesh is considerably refined at the interface near the free edges to obtain accurate results. The size of the elements in this zone is almost 1 micron [7]. The variational model is implemented with two different amounts of ply refinement. First, each ply is divided into 20 elements of equal thickness $(n=20)$. Second, in addition to uniform ply refinement, the elements adjacent to both interfaces have been successively divided in half, three times. In both laminates, far from the free edge, the results obtained from three models are in perfect accordance. However, a large discrepancy between the refined variational and FEM results can be seen, very close to the free edge. Indeed, the variational model with regular ply refinement $(n=20)$ is as accurate as 3D FEM, but the very refined variational model (with the proposed additional ply refinement near interfaces) is much more accurate than the 3D finite element method.

Finally, the problem of interlaminar free edge stress transfer in thin ply composite laminates is discussed. A $[0 / 90]_{\mathrm{s}}$ laminate with standard thickness $\left(\mathrm{t}_{\mathrm{ply}}=0.13 \mathrm{~mm}\right)$ and a $[0 / 90]_{5 \mathrm{~s}}$ laminate with thin plies $\left(\mathrm{t}_{\mathrm{ply}}=0.13 / 5=0.026 \mathrm{~mm}\right)$ made of CTE1/T700 (Eq. (31)) are considered. In order to have the converged results, each ply is first divided into 5 elements with the same thickness and the elements adjacent to both interfaces have been successively divided in fourth, three times, for both standard and thin-ply laminates. Therefore, 28 and 212 ply elements are used to accurately model 
interlaminar stress transfer in standard and thin-ply laminates, respectively. Fig. 7a shows the through thickness distribution of the normalized interlaminar axial $\left(\sigma_{\mathrm{zz}} / \varepsilon_{\mathrm{xx}}\right)$ stresses at the freeedge location $(\mathrm{y}=\mathrm{W})$ for both standard and thin-ply laminates under uniform extension of $\varepsilon_{\mathrm{xx}}$. Fig. $7 \mathrm{~b}$ also shows across the width distribution of normalized interlaminar shear $\left(\sigma_{\mathrm{yz}} / \varepsilon_{\mathrm{xx}}\right)$ stresses at 0/90 interface for both standard $(\mathrm{z}=0.13 \mathrm{~mm})$ and thin-ply $(\mathrm{z}=0.208$, interface with highest interlaminar stresses) laminates. It can be clearly seen that free-edge stresses in thin-ply composite laminates are remarkably lower than standard laminates. Therefore, it is expected that thin-ply laminates have much more strength against free-edge delamination. It is noteworthy that the use of finite element approach when dealing with interlaminar free-edge stress analysis in thin-ply composite laminates is a very difficult task due to the complexity of the required meshes near free edges and interfaces between the plies. Therefore, the current model with capability of modeling more than 200 plies with different orientations can be a very good design tool to anticipate stacking sequence effects on free-edge delamination in thin-ply composite laminates.

\section{Conclusion}

A novel variational model based on the concept of minimum complementary energy is developed to accurately predict both stress and displacement fields in general symmetric laminates containing straight free edges under a uniform longitudinal extension and a uniform temperature change. The approach can only be applied to laminate strips where the length is much larger than the width. The methodology has been formulated analytically and can be applied to free-edge stress analysis of thin-ply composite laminates with arbitrary number of layers. The comparison of results with available FEM results in the literature shows an excellent agreement. The assumed stress/displacement fields satisfy accurately stress equilibrium, strain-displacement relations and the boundary and continuity conditions and also, the minimum complementary energy principle 
and a ply refinement methodology are employed to approach the exact solution. The derived approach, when implemented together with a ply refinement technique, can be considered as a stress-based super element, where highly accurate result can be delivered and continuity of tractions and displacements at all element ply interfaces can be assured. The formulation can be enhanced to deal with un-symmetric laminates and bending loads by considering more stress perturbation functions [16]. This certainly necessitates a future detailed research work.

\section{Acknowledgment}

The first author acknowledges the financial support of Fonds voor Wetenschappelijk Onderzoek FWO-Vlaanderen (Grant No. G009015N).

\section{References}

[1]- Mittelstedt C, and Becker W. Free-Edge Effects in Composite Laminates. ASME Appl. Mech. Rev 2007; 60: 217-45.

[2]- Peng B, Goodsell J, Pipes RB, Yu W. Generalized Free-Edge Stress Analysis Using Mechanics of Structure Genome. ASME J. Appl. Mech 2016; 83: 101013-101013-7.

[3]- Pipes RB, Pagano N. Interlaminar Stresses in Composite Laminates-An Approximate Elasticity Solution. ASME J. Appl. Mech 1974; 4: 668-72.

[4]- Pipes RB, Goodsell J, Ritchey A, Dustin J, Gosse J. Interlaminar Stresses in Composite Laminates: Thermoelastic Deformation. Compos. Sci. Technol 2010; 70:1605-11.

[5]- Pagano NJ. Stress Fields in Composite Laminates. Int J Solids \& Struc 1978; 14:385-400.

[6]- Mittelstedt C, and Becker W. The Pipes-Pagano-problem revisited: Elastic fields in boundary layers of plane laminated specimens under combined thermomechanical load. Composite Structures 2007; 80: 373-95. 
[7]- Saeedi N, Sab K, Caron JF. Delaminated multilayered plates under uniaxial extension. Part II: Efficient layerwise mesh strategy for the prediction of delamination onset. Int J solids \& Structures 2012;49:3727-40.

[8]- Tahani M, Nosier A. Free Edge Stress Analysis of General Cross-Ply Composite Laminates Under Extension and Thermal Loading. Compos. Struc 2003; 60:91-103.

[9]- Sarvestani HY, Sarvestani MY. Free-Edge Stress Analysis of General Composite Laminates Under Extension, Torsion and Bending. Appl. Math. Modell. 2012;36:1570-88.

[10]- Kassapoglou C. Determination of Interlaminar Stresses in Composite Laminates under Combined Loads. J Reinforced Plastics and Composites 1990; 9: 33-58.

[11]- Cho M, Kim HS. Iterative Free-Edge Stress Analysis of Composite Laminates Under Extension, Bending, Twisting and Thermal Loadings. Int. J. Solids Struct 2000; 37: 435-59.

[12]- Zhang D, Ye J, Sheng HY. Free-edge and ply cracking effect in cross-ply laminated composites under uniform extension and thermal loading. Composite Struc 2006; 76: 314-25.

[13]- Nguyen VT, Caron JF. Finite element analysis of free-edge stresses in composite laminates under mechanical an thermal loading. Composites Science and Technology 2009; 69; 40-49. [14]- Hashin Z. Analysis of cracked laminates: a variational approach. Mech Mater 1985; 4:12136.

[15]- Hajikazemi M, Sadr MH. A Variational model for stress analysis in cracked laminates with arbitrary symmetric lay-up under general in-plane loading. Int. J. Solids Struct 2014; 51: 516-29. [16]- Hajikazemi M, Sadr MH, Talreja R. Variational analysis of cracked general cross-ply laminates under bending and biaxial extension. Int J Damage Mech 2015; 24:582-624.

[17]- Hajikazemi M, Sadr MH, H. Hosseini-Toudeshky, B. Mohammadi. Thermo-elastic constants of cracked symmetric laminates: a refined variational approach. Int J Mech Sci 2014; 89: 47-57. 
[18]- Hajikazemi M, McCartney LN. Comparison of Variational and Generalized Plane Strain approaches for matrix cracking in general symmetric laminates. Int J Damage Mech, First published date: January-05-2017, DOI:10.1177/1056789516685381.

[19]- Kassapoglou C, Lagace P. An Efficient Method for the Calculation of Interlaminar Stresses in Composite Materials. ASME J. Appl. Mech 1986; 53: 744-50.

[20]- Wang ASD, Crossman FW. Some New Results on Edge Effect in Symmetric Composite Laminates. J Comp Mater 1977; 11: 92-106.

[21]- Wang ASD, Crossman FW. Edge effects on thermally induced stresses in composite laminates. J Comp Mater 1977; 11: 300-312.

[22]- Nairn JA. Exact and variational theorems for fracture mechanics of composites with residual stresses, traction-loaded cracks, and imperfect interfaces. Int J Fracture 2000; 105: 243-71.

[23]- McCartney LN. Derivations of energy-based modelling for ply cracking in general symmetric laminates. J Composite Materials 2013; 47: 2641-2673.

[24]- Hannaby SA. The solution of ordinary differential equations arising from stress transfer mechanics of general symmetric laminates. NPL Report, 1997 CISE 13/97.

[25]- Rosen BW. Thermoelastic energy functions and minimum energy principles for composite materials. International Journal of Engineering Science 1970; 8: 5-18.

[26]- McCartney LN. Model to predict effects of triaxial loading on ply cracking in general symmetric laminates. Composites Science and Technology 2000; 60: 2255-2279.

\section{Appendix A.}

The admissible displacement fields should satisfy the following displacement boundary and continuity conditions:

1- Symmetry with respect to $x=0$ (mid-plane): 


$$
\mathrm{w}_{1}=0, \quad \text { on } \quad \mathrm{z}=0
$$

2- Displacement continuity condition at the interface between the plies

$$
\mathrm{u}_{\mathrm{i}}=\mathrm{u}_{\mathrm{i}+1}, \quad \mathrm{v}_{\mathrm{i}}=\mathrm{v}_{\mathrm{i}+1}, \quad \mathrm{w}_{\mathrm{i}}=\mathrm{w}_{\mathrm{i}+1}, \quad \text { on } \mathrm{x}=\mathrm{x}_{\mathrm{i}}, \quad \mathrm{i}=1 \ldots \mathrm{N}-1 .
$$

On substituting $\mathrm{z}=\mathrm{Z}_{\mathrm{i}-1}$ in (27) and considering Eqs. (A.1) and (A.2) $)_{3}$, the following recurrence relation is derived for the functions $\mathrm{W}_{\mathrm{i}}(\mathrm{y})$, for $\mathrm{i}=1 \ldots \mathrm{N}$ :

$$
\begin{gathered}
\mathrm{W}_{\mathrm{i}}(\mathrm{y})=\frac{\left(\mathrm{S}_{33}^{\mathrm{i}}-\mathrm{S}_{13}^{\mathrm{i}}{ }^{2} / \mathrm{S}_{11}^{\mathrm{i}}\right) \mathrm{h}_{\mathrm{i}}{ }^{2}}{2}\left[-\frac{1}{3} \mathrm{p}^{\prime \prime}{ }_{\mathrm{i}}(\mathrm{y})+\sum_{\mathrm{j}=1}^{\mathrm{i}} \mathrm{p}^{\prime \prime}{ }_{\mathrm{j}}(\mathrm{y})\right] \\
-\left(\mathrm{S}_{33}^{\mathrm{i}}-\mathrm{S}_{13}^{\mathrm{i}}{ }^{2} / \mathrm{S}_{11}^{\mathrm{i}}\right) \mathrm{h}_{\mathrm{i}}\left[\frac{1}{2} \sum_{\mathrm{j}=1+\mathrm{i}}^{\mathrm{N}}\left(\mathrm{z}_{\mathrm{j}}+\mathrm{z}_{\mathrm{j}-1}\right) \mathrm{p}^{\prime \prime}{ }_{\mathrm{j}}(\mathrm{y})+\mathrm{z}_{\mathrm{i}} \sum_{\mathrm{j}=1}^{\mathrm{i}} \mathrm{p}^{\prime \prime}{ }_{\mathrm{j}}(\mathrm{y})\right] \\
+\left[\mathrm{h}_{\mathrm{i}} \varepsilon_{\mathrm{zz}}^{0(\mathrm{i})}-\left(\mathrm{S}_{23}^{\mathrm{i}}-\frac{\mathrm{S}_{13}^{\mathrm{i}} \mathrm{s}_{12}^{\mathrm{i}}}{\mathrm{S}_{11}^{\mathrm{i}}}\right) \mathrm{p}_{\mathrm{i}}(\mathrm{y})-\left(\mathrm{S}_{36}^{\mathrm{i}}-\frac{\mathrm{s}_{13}^{\mathrm{i}} \mathrm{S}_{16}^{\mathrm{i}}}{\mathrm{S}_{11}^{\mathrm{i}}}\right) \mathrm{q}_{\mathrm{i}}(\mathrm{y})\right]+\mathrm{W}_{\mathrm{i}-1}(\mathrm{y}), \text { where } \mathrm{W}_{0} \equiv 0 .
\end{gathered}
$$

On substituting $\mathrm{z}=\mathrm{Z}_{\mathrm{i}-1}$ in (28), considering continuity condition in Eq. (A.2) 2 and then eliminating $\varepsilon_{\mathrm{yy}}^{0}$ and $\varepsilon_{\mathrm{xy}}^{0}$ by subtraction, the following recurrence relation can be derived for the functions $\Delta V_{i}(y) \equiv V_{i}(x, y)-V_{N}(x, y)$ which must be independent of $x$, for $i=N \ldots 2$ :

$$
\begin{aligned}
& \Delta V_{\mathrm{i}-1}(\mathrm{y})=\left(\mathrm{S}_{33}^{\mathrm{i}}-\frac{\mathrm{S}_{13}^{\mathrm{i}}{ }^{2}}{\mathrm{~S}_{11}^{\mathrm{i}}}\right) \mathrm{h}_{\mathrm{i}}{ }^{3}\left[\frac{1}{24 \mathrm{~h}_{\mathrm{i}}} \mathrm{p}^{\prime \prime \prime}{ }_{\mathrm{i}}(\mathrm{y})-\frac{1}{6} \sum_{\mathrm{j}=1}^{\mathrm{i}} \mathrm{p}^{\prime \prime \prime}{ }_{\mathrm{j}}(\mathrm{y})\right] \\
& +\left(\mathrm{S}_{33}^{\mathrm{i}}-\frac{\mathrm{S}_{13}^{\mathrm{i}}{ }^{2}}{\mathrm{~S}_{11}^{\mathrm{i}}}\right) \mathrm{h}_{\mathrm{i}}{ }^{2}\left[\frac{1}{4} \sum_{\mathrm{j}=1+\mathrm{i}}^{\mathrm{N}}\left(\mathrm{z}_{\mathrm{j}}+\mathrm{z}_{\mathrm{j}-1}\right) \mathrm{p}^{\prime \prime \prime}{ }_{\mathrm{j}}(\mathrm{y})+\frac{1}{2} \mathrm{z}_{\mathrm{i}} \sum_{\mathrm{j}=1}^{\mathrm{i}} \mathrm{p}^{\prime \prime \prime}{ }_{\mathrm{j}}(\mathrm{y})\right] \\
& +\frac{h_{i}}{2}\left[S_{44}^{i} p^{\prime}{ }_{i}(y)+S_{45}^{i} q_{i}^{\prime}(y)+\left(S_{23}^{i}-\frac{S_{13}^{i} S_{12}^{i}}{S_{11}^{i}}\right) p^{\prime}{ }_{i}(y)+\left(S_{36}^{i}-\frac{S_{13}^{i} S_{16}^{i}}{S_{11}^{i}}\right) q^{\prime}{ }_{i}(y)\right] \\
& +\mathrm{h}_{\mathrm{i}}\left[\mathrm{S}_{44}^{\mathrm{i}} \sum_{\mathrm{j}=1}^{\mathrm{i}} \mathrm{p}^{\prime}{ }_{\mathrm{j}}(\mathrm{y})+\mathrm{S}_{45}^{\mathrm{i}} \sum_{\mathrm{j}=1}^{\mathrm{i}} \mathrm{q}^{\prime}{ }_{\mathrm{j}}(\mathrm{y})\right]-\mathrm{h}_{\mathrm{i}} \mathrm{W}^{\prime}{ }_{\mathrm{i}}(\mathrm{y})+\Delta \mathrm{V}_{\mathrm{i}}(\mathrm{y}) \text {, where } \Delta \mathrm{V}_{\mathrm{N}} \equiv 0
\end{aligned}
$$

On substituting $\mathrm{z}=\mathrm{Z}_{\mathrm{i}-1}$ in (29), considering continuity condition in Eq. (A.2) $)_{1}$ and then eliminating $\varepsilon_{\mathrm{xx}}$ and $\varepsilon_{\mathrm{xy}}^{0}$ by subtraction, the following recurrence relation can be derived for the functions $\Delta \mathrm{U}_{\mathrm{i}}(\mathrm{y}) \equiv \mathrm{U}_{\mathrm{i}}(\mathrm{x}, \mathrm{y})-\mathrm{U}_{\mathrm{N}}(\mathrm{x}, \mathrm{y})$ which must be independent of $\mathrm{x}$, for $\mathrm{i}=\mathrm{N} \ldots 2$ : 


$$
\begin{gathered}
\Delta U_{i-1}(y)=S_{45}^{i} h_{i}\left[\frac{1}{2} p^{\prime}{ }_{i}(y)-\sum_{j=1}^{i} p_{j}^{\prime}(y)\right] \\
+S_{55}^{i} h_{i}\left[\frac{1}{2} q_{i}^{\prime}(y)-\sum_{j=1}^{i} q_{j}^{\prime}(y)\right]+\Delta U_{i}(y), \quad \text { where } \Delta U_{N}(y) \equiv 0 .
\end{gathered}
$$

The functions $\mathrm{V}_{\mathrm{N}}(\mathrm{x}, \mathrm{y})$ and $\mathrm{U}_{\mathrm{N}}(\mathrm{x}, \mathrm{y})$ defined (A.4) and (A.5), can be calculated using throughthickness averages of the Eqs. (3) and (4).

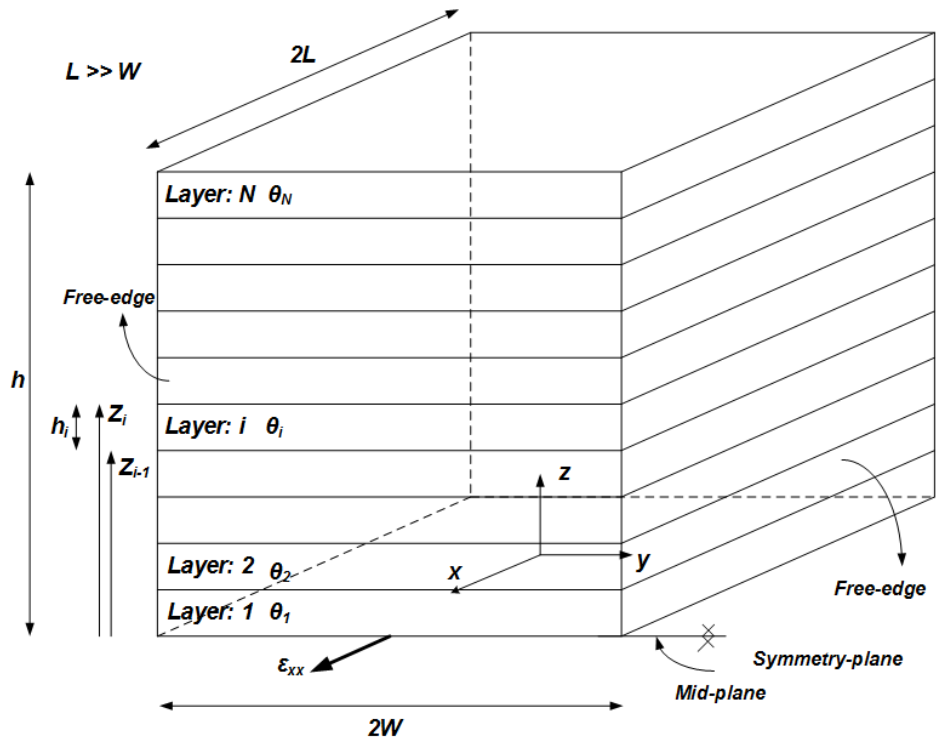

Fig. 1. Geometry of an arbitrary symmetric laminate containing free edges (only the upper set of $\mathrm{N}$ layers ( $\mathrm{z}>0)$ is shown). 


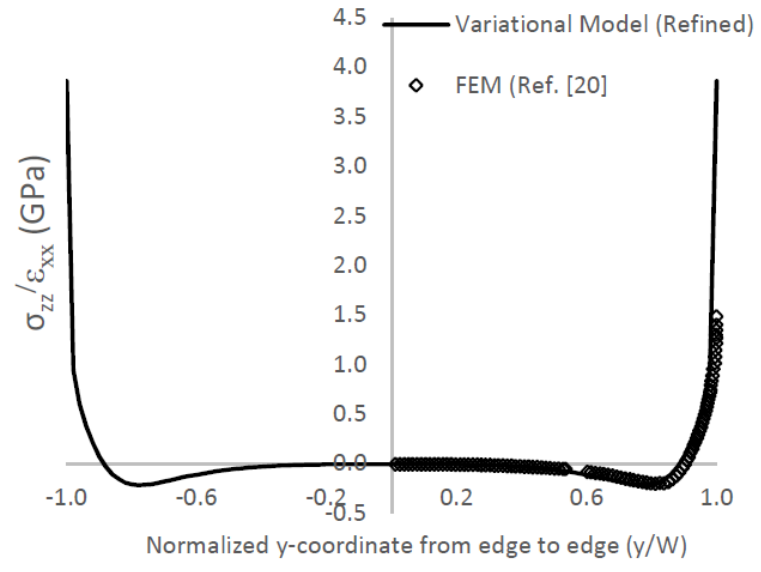

(a)

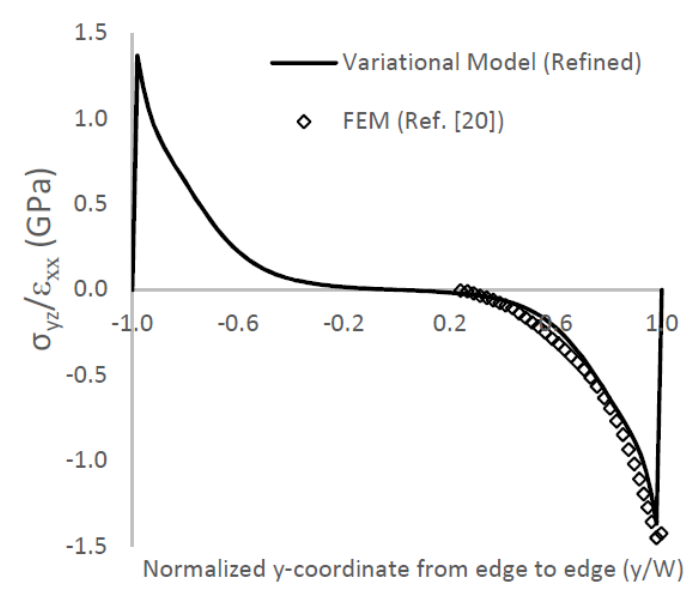

(b)

Fig. 2. Distribution of a) the normalized interlaminar axial $\sigma_{z z}$ and b) shear $\sigma_{y z}$ stresses in ydirection from edge to edge at the $0 / 90$ interface of $[0 / 90]_{\mathrm{s}}$ laminate under $\varepsilon_{\mathrm{xx}}$.

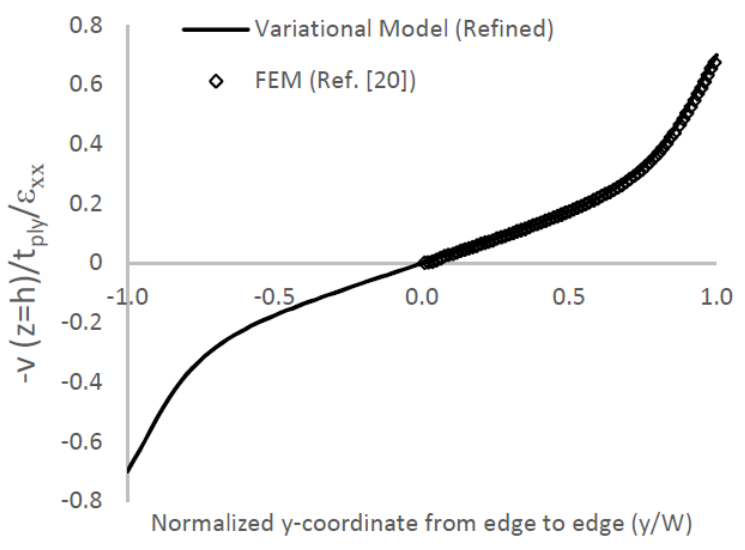

(a)

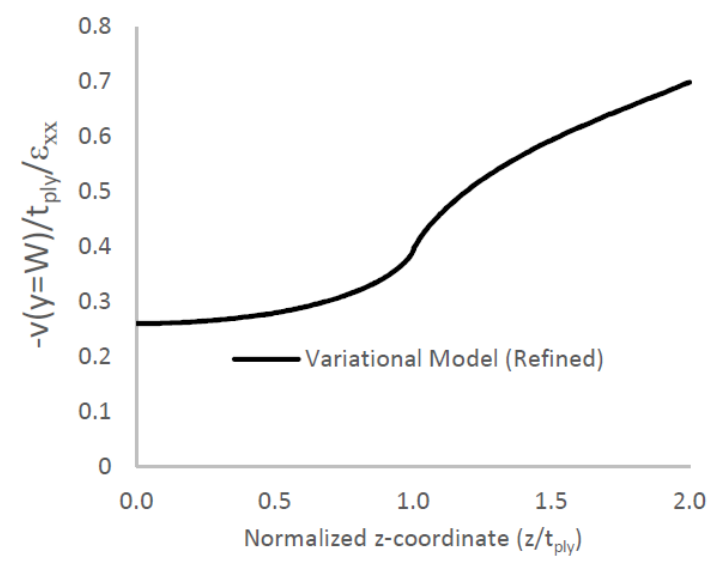

(b)

Fig. 3. a) Across the width distribution of the normalized transverse displacement at top surface $(\mathrm{z}=\mathrm{h})$. b) Through thickness distribution of the normalized transverse displacement at free edge $(\mathrm{y}=\mathrm{W})$ of $[0 / 90]_{\mathrm{s}}$ laminate under $\varepsilon_{\mathrm{xx}}$. 


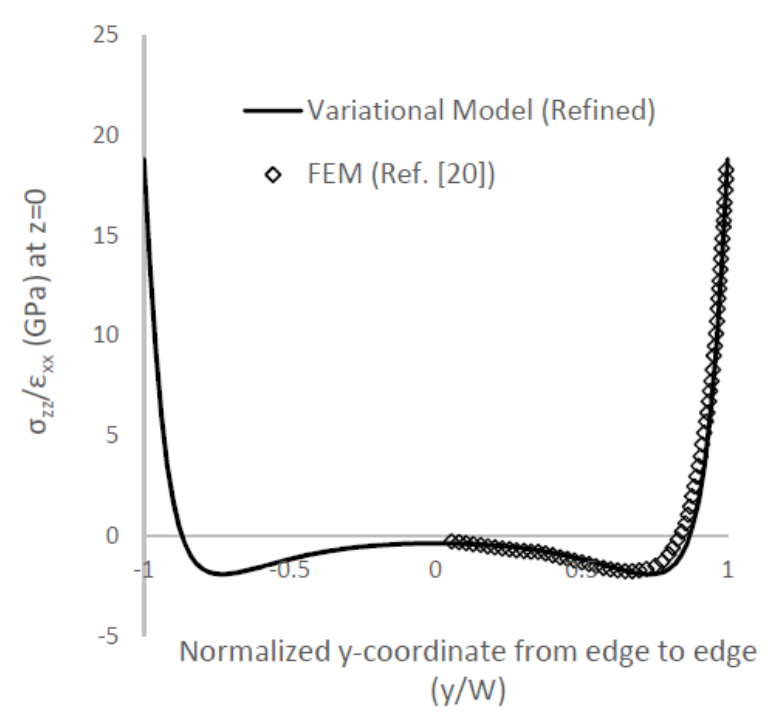

(a)

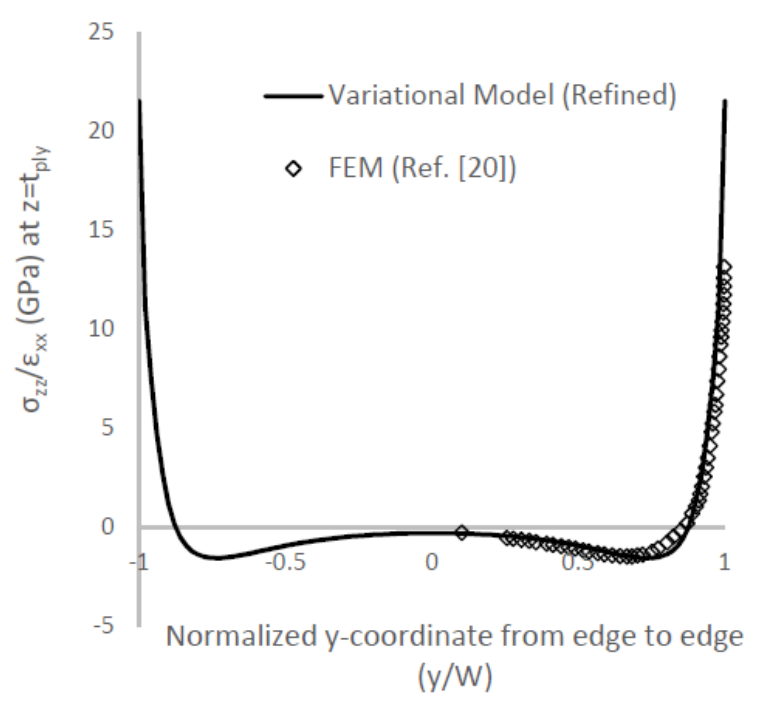

(b)

Fig. 4. Distribution of the normalized interlaminar axial $\sigma_{\mathrm{zz}}$ stresses across the width from edge to edge a) at the mid-plane $(\mathrm{z}=0)$ and $\mathrm{b}$ ) at the $0 / 90$ interface of $[45 /-45 / 90 / 0]_{\text {s laminate }}$ under $\varepsilon_{\mathrm{xx}}$.

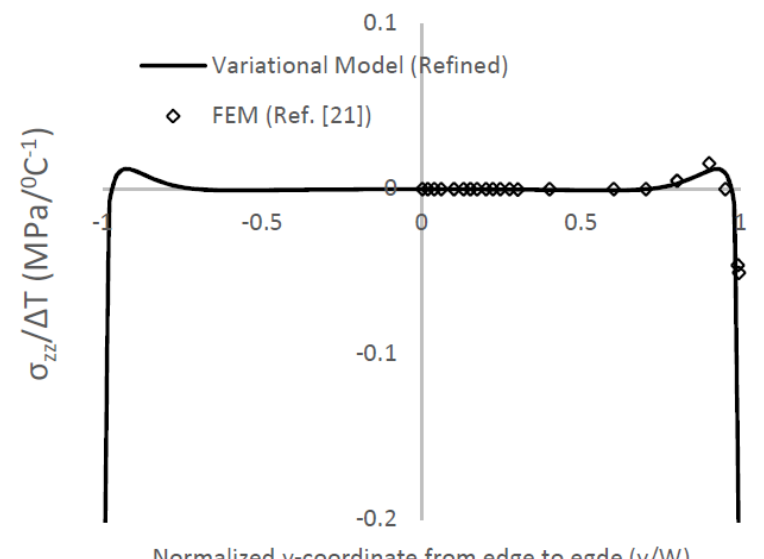

Normalized $y$-coordinate from edge to egde $(y / W)$

(a)

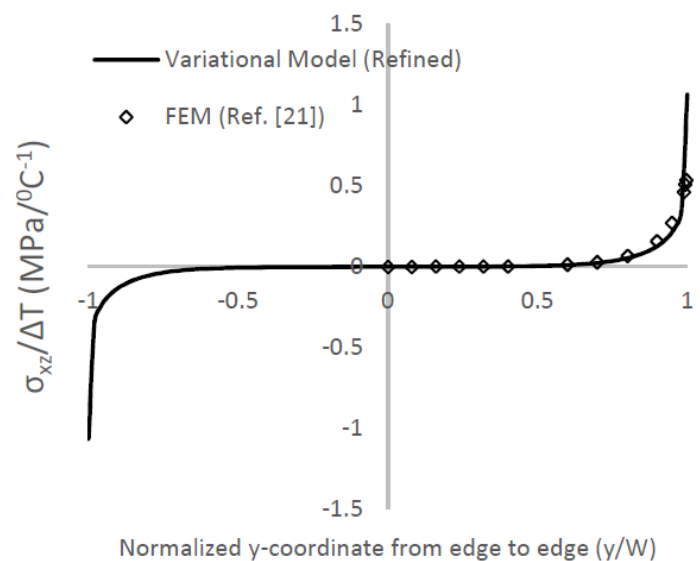

(b)

Fig. 5. Distribution of a) the normalized interlaminar axial $\sigma_{z z}$ and b) shear $\sigma_{x z}$ stresses in ydirection from edge to edge at the 45/-45 interface of a [45/-45]s laminate under $\Delta \mathrm{T}$. 

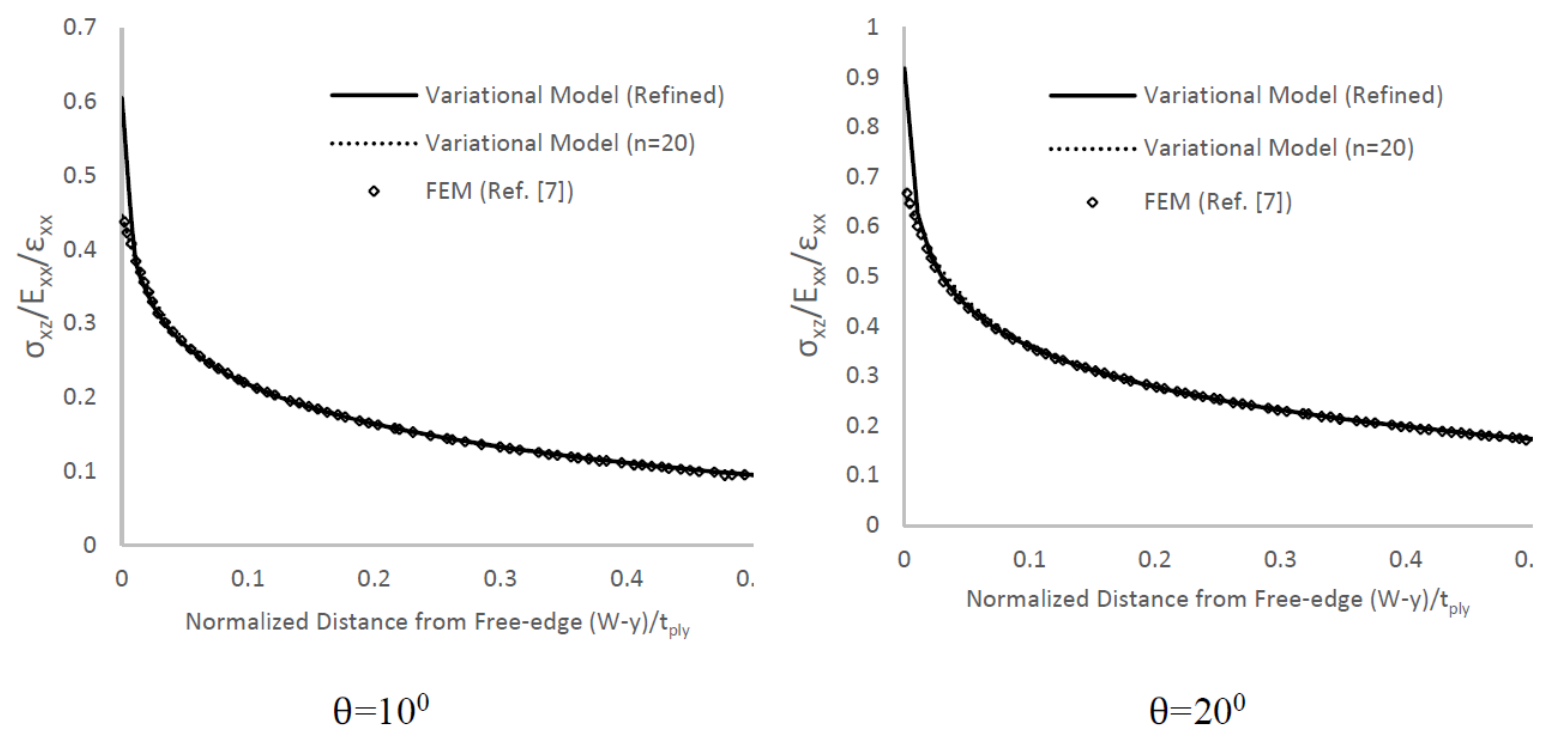

Fig. 6. Distribution of the normalized interlaminar shear stress $\sigma_{x z}$ versus normalized distance from free edge at the interface $\theta /-\theta$ of $[-\theta / \theta]_{\mathrm{s}}$ laminates made of CTE1/T700 under $\varepsilon_{\mathrm{xx}}$.

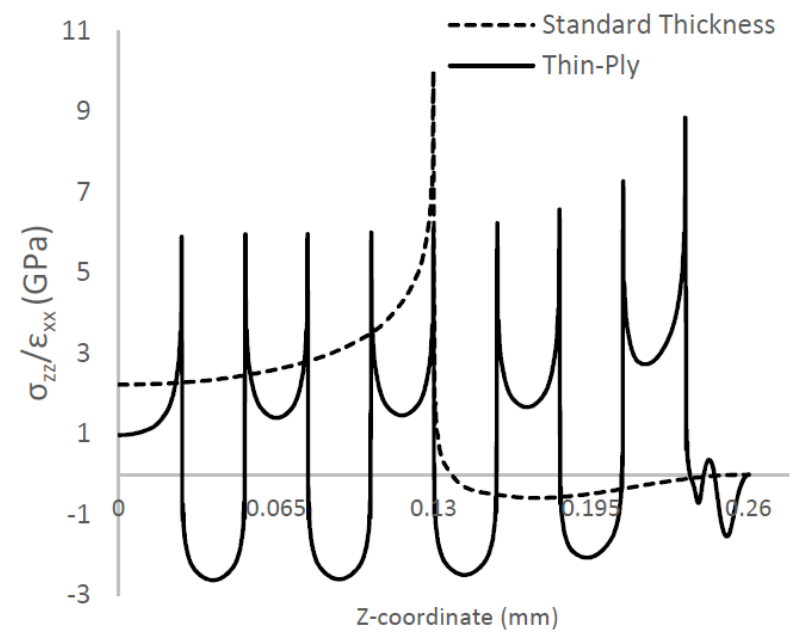

(a)

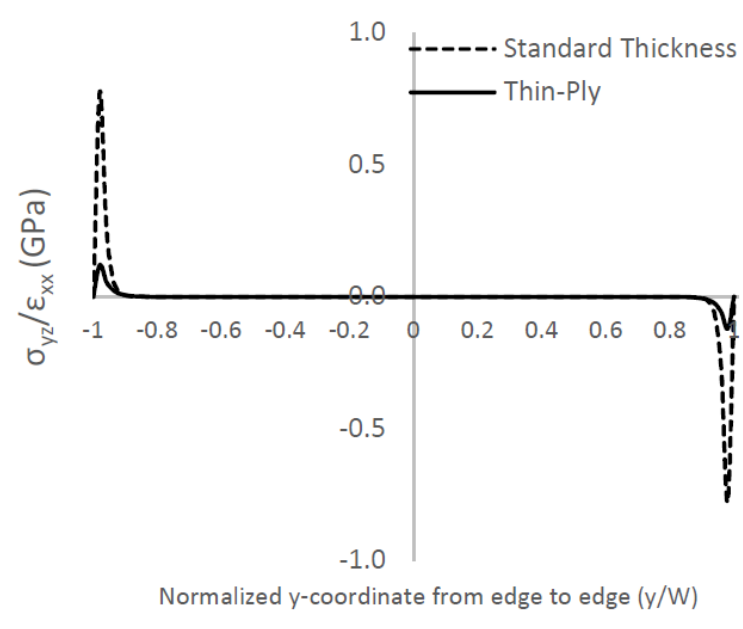

(b)

Fig. 7. a) Through thickness distribution of normalized interlaminar axial stress $\sigma_{z z}$ at freeedge $(y=W)$. b) Across the width distribution of normalized shear stress $\sigma_{y z}$ at $0 / 90$ interface. 